\title{
Episcissors-60 for Mediolateral Episiotomy: Evaluation of Clinical and Economic Evidence to Inform NICE Medical Technologies Guidance
}

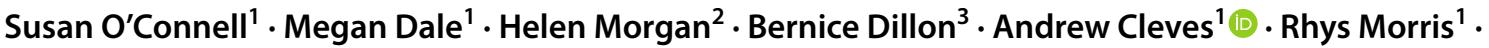 \\ Grace Carolan-Rees ${ }^{1}$
}

Accepted: 21 October 2021 / Published online: 16 November 2021

(c) The Author(s) 2021

\begin{abstract}
Obstetric anal sphincter injury (OASI) occurs in $2.9 \%$ of all vaginal births in the UK and can result in faecal incontinence. Where there is a clinical need for episiotomy, OASI can be minimised by accurate selection of the optimum angle of mediolateral episiotomy. Episcissors-60 are adapted surgical scissors incorporating a guide-limb to help achieve an accurate angle of mediolateral episiotomy. The ability of Episcissors-60 to reduce OASI by preventing inaccurate visual estimates of episiotomy angles was considered by the National Institute of Health and Care Excellence (NICE) as part of the Medical Technologies Evaluation Programme (MTEP). NICE concluded that Episcissors-60 shows promise for mediolateral episiotomy both in terms of clinical effectiveness and potential cost savings, but that there was not enough evidence to support routine adoption into the NHS at this time. NICE MTG47 recommends that key gaps in the evidence including patientreported outcomes and the addition of Episcissors-60 to care bundles be addressed through research with specific focus on potential equality considerations.
\end{abstract}

\section{Key Points for Decision Makers}

National Institute of Health and Care Excellence (NICE) concluded that Episcissors-60 show promise for mediolateral episiotomy, but there is currently not enough evidence to support the case for routine adoption in the

Andrew Cleves

Andrew.cleves@wales.nhs.uk

Susan O'Connell

Susan.OConnell@wales.nhs.uk

Megan Dale

Megan.Dale@wales.nhs.uk

Helen Morgan

MorganHE1@ cardiff.ac.uk

Bernice Dillon

Bernice.Dillion@nice.org.uk

Rhys Morris

Rhys.morris@wales.nhs.uk

Grace Carolan-Rees

grace.carolanrees@gmail.com

1 Cedar, Cardiff and Vale University Health Board, Cardiff, UK

2 Cedar, Cardiff University, Cardiff, UK

3 National Institute for Health and Care Excellence, Manchester, UK
National Health Service (NHS). Research is recommended to address uncertainties about the efficacy and safety of using Episcissors-60.

Because not much good evidence is available, NICE recommends that new studies are done to determine with more certainty whether Episcissors-60 are better than standard scissors, when used with other best-practice care measures to prevent obstetric anal sphincter injury (OASI).

\section{Introduction}

The paper is part of a series that provides insight into the development of National Institute for Health and Care Excellence (NICE) Medical Technologies Guidance (MTG) [1]. NICE MTG makes recommendations on new or innovative 
medical devices or diagnostics. The aim of the guidance is to support adoption of clinically effective and cost saving technologies in the UK National Health Service (NHS).

This paper summarises Cedar's assessment report [2] and discusses how it was used to inform the recommendations of NICE MTG 47 on Episcissors-60 for mediolateral episiotomy [3]. Cedar is a healthcare technology research centre formed through collaboration between Cardiff and Vale University Health Board and Cardiff University.

\subsection{Background to Technology and Application}

Episiotomy is an incision made to the tissue around the vaginal opening to assist safe delivery of the baby, where there is difficulty delivering the baby's head through the vaginal opening, at the crowning stage. Episiotomy is intended to prevent serious perineal tears that can lead to obstetric anal sphincter injury (OASI) which occurs in $2.9 \%$ of all vaginal births in the UK and can result in faecal incontinence [4]. The NICE clinical guideline CG190 'Intrapartum care for healthy women and babies' recommends that an episiotomy should be performed where there is a clinical need, such as instrumental birth or suspected foetal compromise, and that episiotomy should not be performed routinely during spontaneous vaginal birth [5]. The guideline also recommends that an episiotomy should use a mediolateral technique encompassing an angle of between $45^{\circ}$ and $60^{\circ}$ from the vertical axis [5]. There is evidence that achievement of an optimal angle within this range reduces the incidence of OASI, and also that doctors and midwives fail to achieve the optimal angle of episiotomy by visualisation alone [6].

The 2019 National Maternity and Perinatal audit reported that out of 400,386 women in England who had a vaginal, cephalic delivery of a singleton baby at term, $21.6 \%$ had an episiotomy. Of 20,150 women in Wales, $21.1 \%$ had episiotomy [7]. A systematic review and meta-analysis of a large number of women undergoing vaginal birth, most of whom were nulliparous, concluded that mediolateral episiotomy has a beneficial effect in prevention of OASI [8]. In 150,068 nulliparous/multiparous births with episiotomy, the rate of OASI was $1.8 \%$, and in nulliparous births with episiotomy the rate of OASI was $2.1 \%$ [8]. Therefore mediolateral episiotomy retains some risk of OASI.

Episcissors-60 are adapted surgical scissors, available as either a reusable or disposable, single use medical device, for performing episiotomy. The scissors have 5-cm-long blades and the key component is a guide-limb mounted at the blade pivot point and angled at $60^{\circ}$ from the blades. During episiotomy the doctor or midwife aligns the guide limb in the vertical axis and this aims to ensure that the correct angle of episiotomy is achieved, preventing inaccurate visual estimation of the angle and reducing the incidence of OASI. Episcissors-60 are available with straight handles or angled handles for ergonomic handling, but in either case the guide limb is angled at $60^{\circ}$ from the blades.

\subsection{Decision Problem (Scope)}

The scope of NICE MTG is defined by NICE in the form of a PICO table (population, intervention, comparator, outcomes; plus cost analysis and subgroups to be considered). In its evidence submission, the company must keep within the scope of the evaluation or provide a rationale for any variance.

\subsection{Population}

The population included women who have a clinical need for an episiotomy, including instrumental deliveries in cases of suspected foetal compromise.

\subsection{Intervention}

The intervention was defined as being reusable Episcissors-60.

\subsection{Comparator}

The comparator was standard reusable or standard disposable episiotomy scissors.

\subsection{Outcomes}

The outcomes defined in the scope included procedural outcomes such as device-related adverse events, incidence and severity of OASI, complication rates (wound breakdown, infections, faecal incontinence and postpartum haemorrhage), ease of use, operator learning curve, cost of complications, post-delivery suture angles, length of episiotomy and post-delivery distance from midline. Patient-specific outcomes included length of stay and quality of life.

\subsection{Equality and Diversity}

Women of Asian family origin may be more at risk of OASI due to a shorter perineal body length. The National Maternity and Perinatal Audit reports that $12.4 \%$ of births in England were to women of Asian ethnicity [9]. One retrospective cohort study in California $(n=22,741)$ reported an increased risk of OASI in Asian women compared with White women (adjusted odds ratio [aOR] 2.31; 95\% confidence interval [CI] 1.99-2.69) [10]. A second cohort study ( $n=32,653$ births) in Australia reported an increased risk of OASI in South Asian (aOR 2.6; 95\% CI 2.2-3.3) and South East/East Asian women (aOR 2.1; 95\% CI 1.7-2.5) compared with White women [11]. The National Maternity 
and Perinatal Audit did not report the incidence of OASI by ethnicity [9].

\section{Cedar's Review of the Evidence}

The company, Medinvent Ltd, provided an evidence submission to NICE presenting the available clinical and cost evidence, alongside a de novo cost model produced by the company. Cedar's assessment report aimed to provide the NICE Medical Technologies Advisory Committee (MTAC) with a balanced and independent appraisal of the evidence surrounding the use of Episcissors-60 for mediolateral episiotomy [2].

\subsection{Review of Clinical Effectiveness Evidence}

To ensure that all relevant literature had been identified and submitted by the company, Cedar undertook its own literature search across 10 databases, using a range of freetext terms and subject headings. Following study selection against the Scope document, Cedar considered that five published studies [12-16] and four unpublished studies [17-20] were relevant to the decision problem. Of the published studies, one was a cohort design [15], two were before and after studies $[13,16]$ and two were case series $[12,14]$. The unpublished studies comprised of a before and after study [17] and a case series [20], however there were insufficient details for two studies $[18,19]$. The unpublished before and after study conducted in the North East of England [17] has since been published in a peer review journal with no substantial changes [21]. Cedar assessed the quality of the evidence using GRADE software [22]. This showed that the quality of the published studies was low, with a high risk of bias; there was insufficient information to assess the unpublished studies. Seven studies were conducted in the UK [12, $13,16-20]$ and two in India $[14,15]$. In the published studies, patient numbers ranged from 17 [12] to 2566 [13].

The evidence considered by Cedar indicated that use of Episcissors-60 resulted in episiotomy post-suture angles within the safe range recommended by NICE guidance [5]. Individual study outcomes and results are presented in Table 1. In addition, the Cedar performed meta-analysis using Cochrane Rev Man software [23]. Pooled analysis conducted by the Cedar of five studies [13, 15-18] suggests no significant risk difference (RD) for OASI rate in women who had an episiotomy with Episcissors-60 compared with standard episiotomy scissors (RD - 0.02; 95\% CI - 0.05 to $0.01 ; p=0.14$, Fig. 1). The Cedar's pooled analysis of two studies $[13,16]$ indicates that Episcissors-60 as part of a bundle of care may significantly reduce OASI rates in women who have an episiotomy (RD $-0.04 ; 95 \% \mathrm{CI}-0.08$ to $-0.00 ; p=0.03)$, though the heterogeneity between the studies remained high $\left(I^{2}=70 \%\right)$ (Fig. 2).

Two studies reported that following introduction of Episcissors- 60 , the rate of episiotomy increased by $11 \%$ overall [16] and $15 \%$ overall [13], while one unpublished study [17] reported no change in the rate of episiotomies with the introduction of Episcissors-60. Two clinical experts, consulted as part of the NICE process, suggested that it is possible that the introduction of Episcissors-60 might result in a behaviour change with clinical staff; one clinical expert reported a small increase in episiotomies since the introduction of Episcissors-60 and two clinical experts indicated that the introduction of Episcissors-60 has increased awareness of the need for episiotomies and appropriate technique.

\subsection{Safety Outcomes}

Cedar did not identify any adverse events specifically related to the use of Episcissors-60. It was noted that all reusable scissors have the potential to become blunt over time and need regular resharpening. However re-usable Episcissors-60 are being phased out and disposable versions introduced, therefore the issue will not be relevant.

\subsection{Review of Economic Evidence}

One non-peer reviewed report [24] was identified, presenting a return on investment calculation. The company concluded that it did not contain sufficient information and that a de novo model was required. The Cedar agreed with their assessment.

\subsubsection{Episcissors-60 Model Structure}

The model structure is a simple decision tree with arms for Episcissors-60 and standard scissors (Fig. 3). Each arm has branches for OASI repair or no OASI repair. The time horizon is 1 year, so no discounting was applied and the perspective is NHS.

\subsubsection{Key Assumptions}

The key assumptions in the accepted base model are:

- The cohort in the model is 94,000 women having episiotomy.

- The cost per use of standard episiotomy scissors is based on the cost of standard reusable scissors from the NHS supply chain (data commercial in confidence).

- The cost per use of Episcissors-60 is $£ 16$ giving a cost per birth of $£ 2.40$ (Company submission).

- The cost of OASI repair based on NHS improvement costs is $£ 1956$ [25]. 


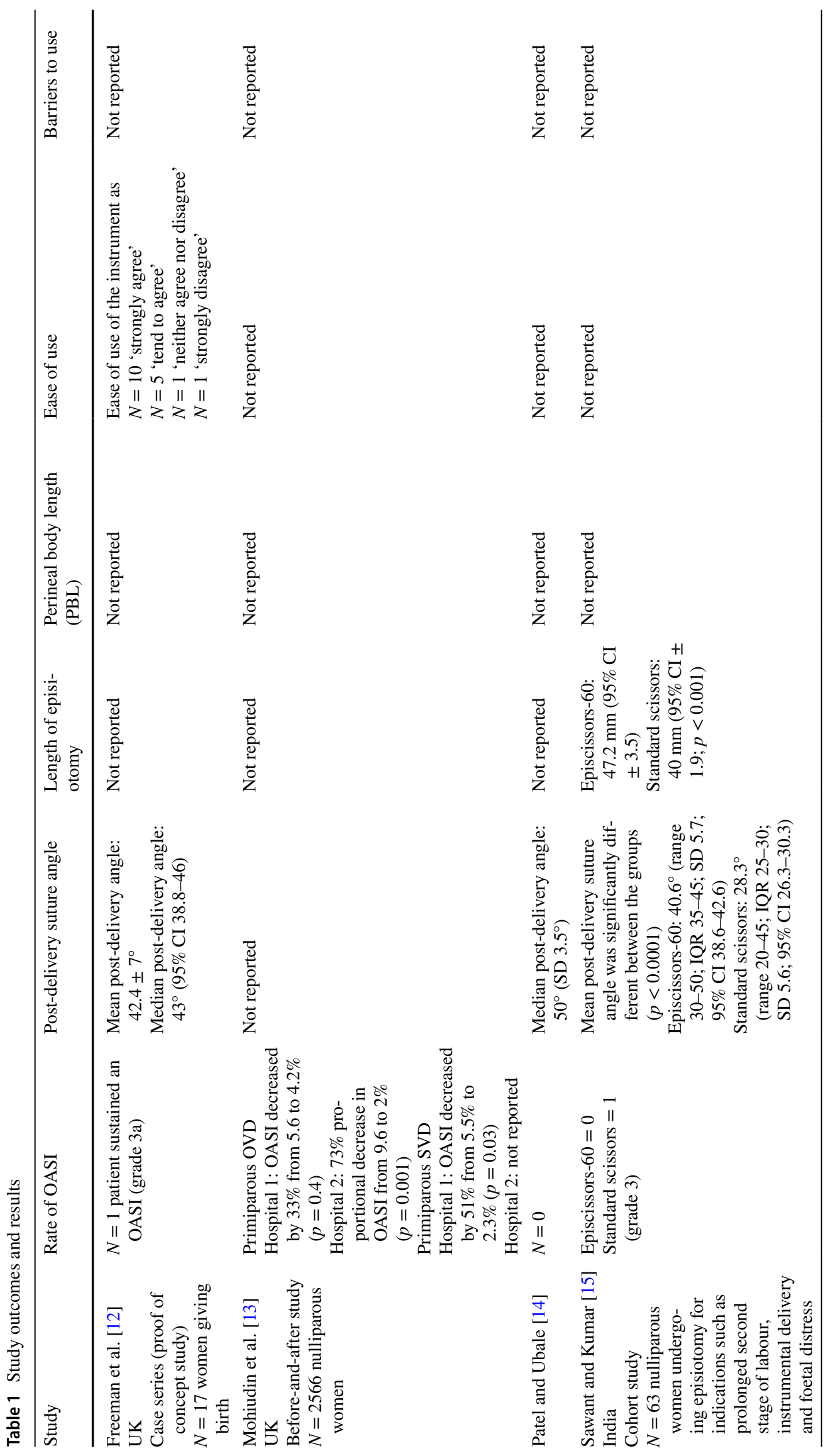




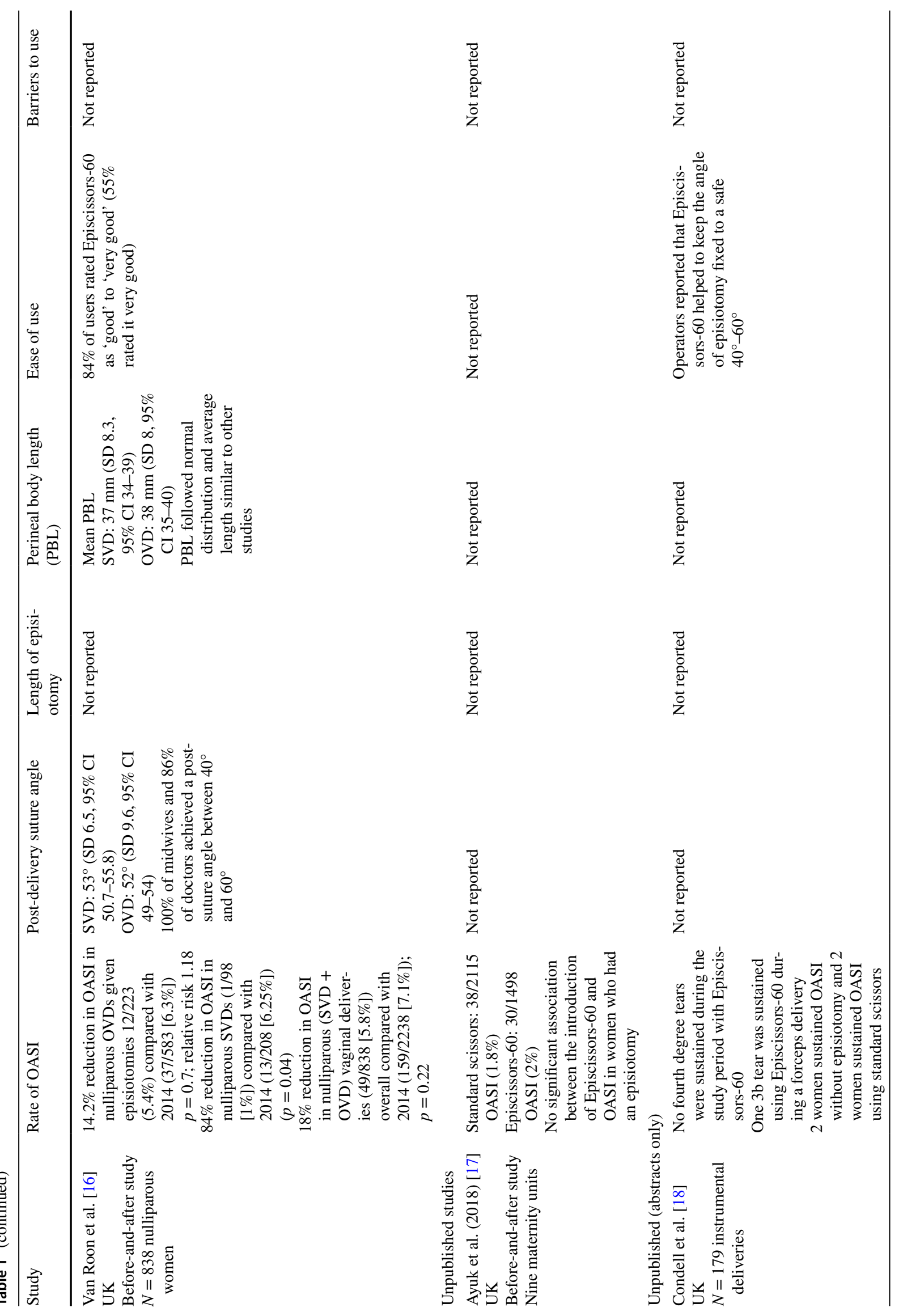




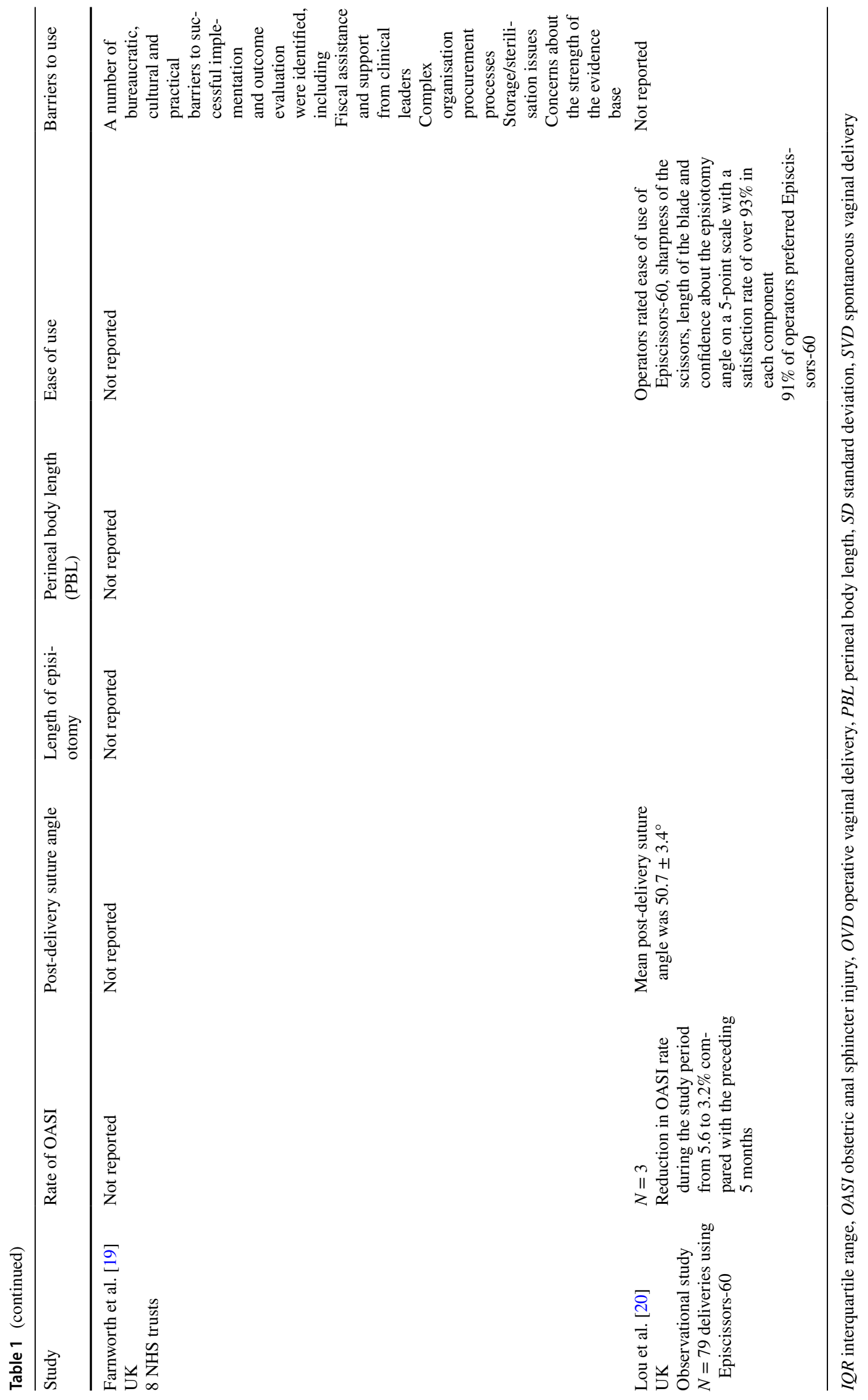




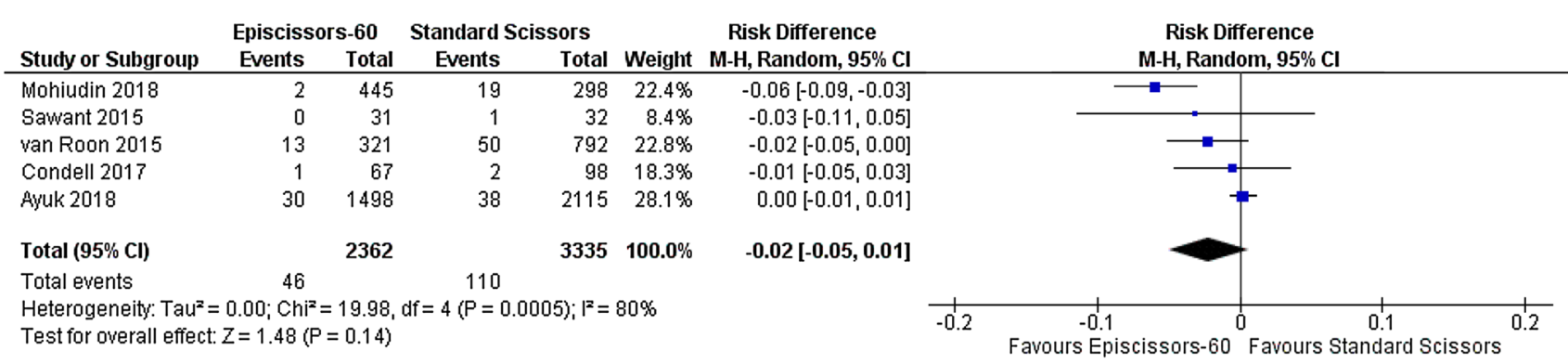

Fig. 1 Obstetric anal sphincter injuries in deliveries with episiotomy performed with Episcissors-60 versus standard scissors including all studies with reportable data

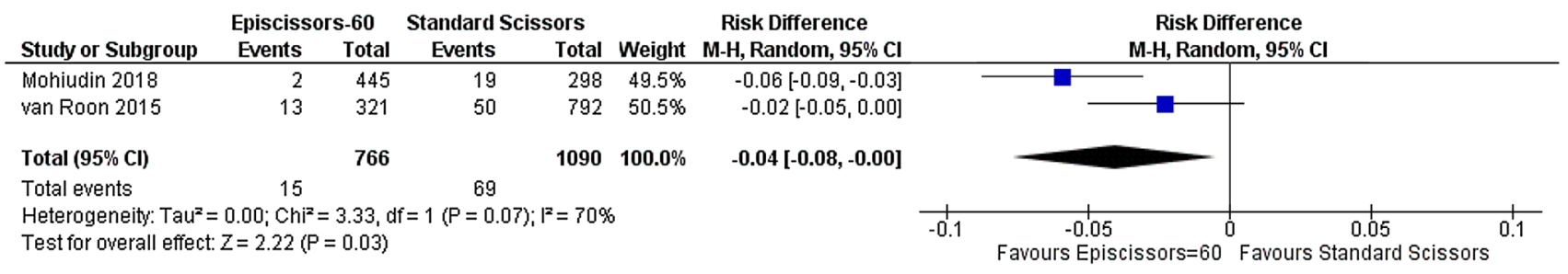

Fig. 2 Obstetric anal sphincter injuries (OASI) in deliveries with episiotomy performed with Episcissors-60 versus standard scissors including only studies which included other interventions to reduce OASI

Fig. 3 Episcissors-60 decision tree

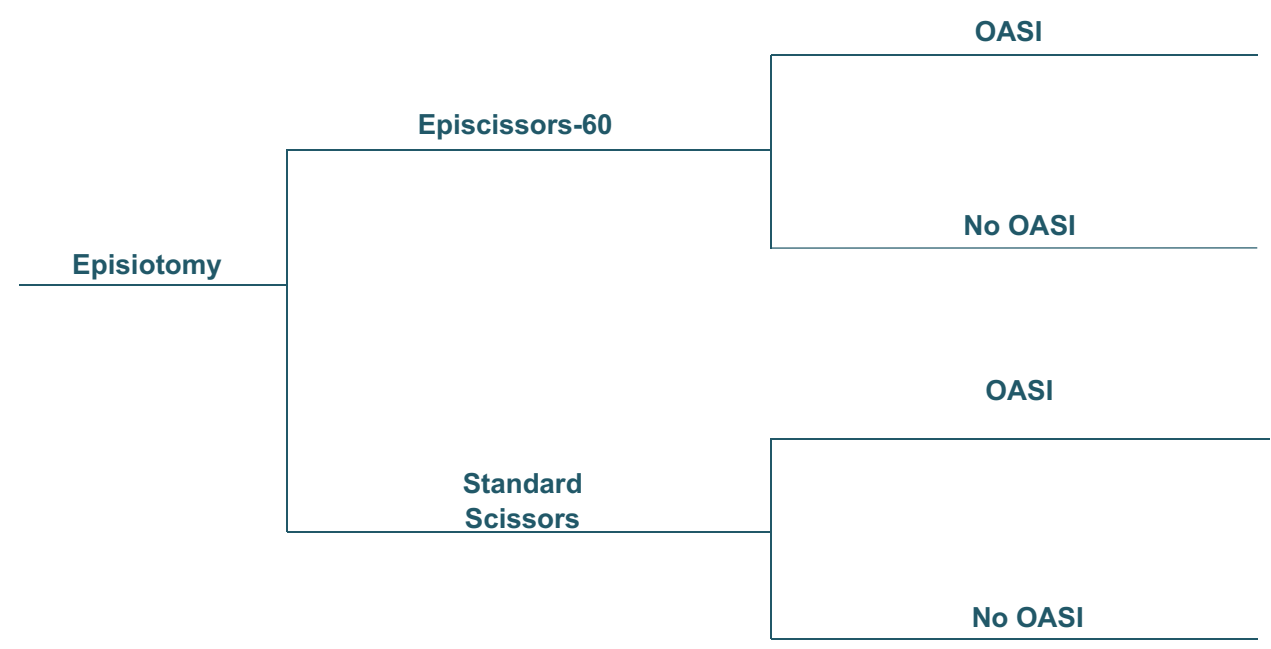

- The cost of an excess bed day based on NHS improvement costs is £366 [25].

- The incidence of OASI using standard scissors is $5.1 \%$ of all births based on Royal College of Obstetricians and Gynaecologists guidance [26].

- The reduction in OASI using Episcissors-60 is 39\% based on Cedar's meta-analysis of five studies [13, 15-18].

\subsubsection{Data Sources for Outcomes and Resources}

Resource use is based on use of Office of Population, Censuses and Surveys' Classification of Surgical Operations and Procedures (OPCS) codes to identify codes for repair of third and fourth degree lacerations. The corresponding Healthcare Resource Group (HRG) code was used to identify the cost of an OASI repair using the 2019/20 National Non-Mandatory Tariff without the market forces factor (MFF). Rates of OASI are taken from published literature [4, 13]. 
The relevant OPCS codes were R322 (repair of obstetric laceration of perineum and sphincter of anus) and R325 (repair of laceration of perineum and sphincter and mucosa of anus), which correspond with HRG NZ27Z (post-natal therapeutic procedures).

\subsubsection{Changes by Cedar}

Cedar made a number of changes to the company economic submission, including:

- The use of NHS reference costs to identify cost of OASI repair.

- The use of NHS Supply Chain costs for comparator scissors.

- Population included in the model was the women having an episiotomy in line with scope.

- Changes to the rates of OASI before introduction of Episcissors-60.

- Changes to the percentage rate reduction in OASI through use of Episcissors-60.

\subsubsection{Results from the Model}

The model submitted by the company found reusable Episcissors-60 to be cost saving at $£ 20.57$ per patient compared with standard disposable scissors (Table 2).

Following changes made by the Cedar, the results of the model found Episcissors-60 to save $£ 30.70$ per patient with sensitivity analysis (across multiple variables simultaneously), indicating a highest cost saving estimate of $£ 70.17$ and a lowest estimate of $-£ 38.96$ (cost incurring) per patient.

\subsubsection{One-Way Sensitivity Analysis, Scenarios and Key Drivers}

The company submission included one-way sensitivity analysis, which explored the impact of changing input parameters in the intervention arm only. The Cedar noted that there were no low or high values included in the model for any parameters other than OASI rates.
Cedar conducted one-way sensitivity analysis to explore the impact of changing inputs in both the intervention and comparator arms. The key driver in the model is the OASI rate in the comparator (standard scissors) arm. The lower the rate of OASI in the baseline, the less impact the introduction of Episcissors-60 can have on rates of OASI; therefore, the potential for cost savings is reduced and there is a possibility that Episcissors-60 could be cost incurring. When varying the cost of Episcissor-60, cost of standard scissors and the cost of OASI repair and excess length of stay, sensitivity analysis of single variables shows the model remains cost saving.

\subsubsection{Scenario Analysis}

Cedar included two additional scenario analyses to assess the impact of possible clinical scenarios, including

- a re-usable Episcissors-60 may be used up to 50 times before it is disposed of. The impact of this would be to reduce the per-use cost of Episcissors-60;

- cost of standard disposable scissors is increased to reflect that, due to manufacturing processes, the cost of one pair of single-use disposable scissors may be higher than the cost per use of a pair of reusable scissors.

NHS reference cost NZ27Z includes some costs related to length of stay. There was some uncertainty as to whether additional length of stay attributed to OASI should be included in the cost model. Further exploratory analysis in which this additional length of stay was excluded from the model resulted in reduced cost savings associated with Episcissors-60 from $£ 30.70$ to $£ 23.38$.

\section{NICE Guidance}

\subsection{Development of Guidance}

The NICE Medical Technologies Advisory Committee (MTAC) met in September 2019 and considered the evidence from a range of sources, including the company's submission, Cedar's assessment report and advice from clinical
Table 2 Results of scenario analysis compared with basecase results

\begin{tabular}{llcc}
\hline & $\begin{array}{l}\text { Reusable Episcis- } \\
\text { sors-60 }\end{array}$ & $\begin{array}{l}\text { Standard disposable } \\
\text { scissors }\end{array}$ & $\begin{array}{l}\text { Cost saving } \\
\text { per patient }\end{array}$ \\
\hline Company base case & $£ 32.80$ & $£ 53.36$ & $£ 20.57$ \\
Cedar base case & $£ 87.98$ & $£ 118.68$ & $£ 30.70$ \\
Scenario 1: Episcissors-60 used 50 times & $£ 78.38$ & $£ 118.68$ & $£ 40.30$ \\
$\begin{array}{l}\text { Scenario 2: cost of disposable scissors is greater } \\
\text { than cost of reusable scissors }\end{array}$ & $£ 87.98$ & $£ 122.42$ & $£ 34.44$ \\
\hline
\end{tabular}


experts and patient organisations. The committee made provisional guidance recommendations that were published for public consultation on the NICE website.

\subsection{Consultation}

During the consultation process, NICE received a total of 40 consultation comments from eight consultees including NHS professionals and company representatives. Comments covered issues including additional evidence, draft recommendations and wording changes. The comments were discussed at a second MTAC in November 2019. As part of the Innovation and Technology Payment Programme (ITP), NHS England have included Episcissors-60 in the technologies eligible for an innovative technology tariff. Information based on hospital episode statistics data from some trusts that used the technology was presented to the committee. The company clarified in the consultation that both the reusable and single-use versions of the technology will be available to the NHS. Following the committee discussion, minor amendments were made to the recommendations and additional information was added to the guidance to clearly distinguish the Royal College of Obstetricians and Gynaecologists (RCOG) guidelines on the management of third and fourth degree perineal tears [26] and the OASI care bundle supported by RCOG and the Royal College of Midwives [27] and to highlight the potential issue of waste that may be associated with Episcissors-60.

\subsection{Recommendations}

The final recommendations in NICE MTG 47 [3], published in February 2020, are that (1) Episcissors-60 show promise for mediolateral episiotomy, but there is currently not enough evidence to support the case for routine adoption in the NHS; and (2) research is recommended to address uncertainties about the efficacy and safety of using Episcissors-60. This research should

- determine if using Episcissors-60 in addition to other care bundle measures is more effective in achieving an optimal episiotomy angle and in preventing OASI than standard episiotomy scissors;

- include patient-reported outcome measures;

- address potential equality considerations by ensuring patients at greatest risk of OASI are recruited;

- determine the relative cost of using Episcissors-60 compared with standard episiotomy scissors.

\section{Key Challenges and Learning Points}

Cedar noted that the evidence relating to Episcissors-60 is taken from a small number of low quality, non-randomised studies. In some studies, Episcissors-60 was not the only intervention to have been introduced, which makes it difficult to accurately estimate the effectiveness of Episcissor-60 in isolation. The OASI bundle recommends, beside correct episiotomy angle, providing information on OASI to women, providing manual perineal support, and examining, grading and documenting any perineal tears [27].

The rates of OASI are variable across the published literature and, as noted previously, the extent to which Episcissors-60 will be clinically effective or cost saving will depend on the existing rates of OASI in the hospitals or maternity units where it is introduced. A statistically significant difference may not represent a clinically important difference and it is likely that achieving a 'zero' rate of OASI with Episcissors-60 is not clinically possible for all hospitals and trusts given the number of other factors at play. Clinicians should therefore consider their own clinical experience when determining what reductions in OASI might be achievable and the degree to which Episcissors-60 might contribute to a reduction.

There are some clear equality concerns, with women of Asian family origin at increased risk of OASI due to a shorter perineal body length. It is therefore imperative that any research includes a representative population of women to ensure that the impact of Episcissors- 60 can be accurately assessed for all important subgroups.

None of the studies included any patient-reported outcomes exploring the experiences of women who have had an episiotomy using Episcissors-60. OASI repair can impact sexual function and quality of life and it is important that patient-reported outcomes, including patient-reported experience measures are included in future studies to assess the impact of the process of care on the women undergoing episiotomies with Episcissors-60.

\section{Conclusions}

The introduction of Episcissors- 60 has the potential to be both clinically effective and cost saving by making episiotomies safer for women by reducing the need for inaccurate visual estimations of cutting angles. If the use of Episcissors-60 reduces OASI compared with standard scissors there will be cost savings to the NHS; however, the extent of the cost savings will depend on both the baseline rate of OASI before introduction of Episcissors-60 and the impact of Episcissors- 60 on the baseline rate. 
Cedar noted that some of the clinical evidence is drawn from studies that introduced additional interventions at the same time as Episcissors-60 as part of the development of bundles of care. It is therefore possible that any improvements in the rate of OASI may be the result of the combined effect of interventions in the bundles of care.

\section{Declarations}

Author contributions SO, MD, HM, AC, RM, BD and GC-R contributed to the preparation of this manuscript. GC-R reviewed the full assessment report as well as this article. RM reviewed the article and can act as a guarantor for the overall content.

Compliance with ethical standards Susan O'Connell, Megan Dale, Andrew Cleves and Rhys Morris and are employees of the NHS and Grace Carolan-Rees was an employee of the NHS until September 2020 , which has a financial interest in the guidance on which this project is based. Helen Morgan is a Cardiff University employee and has no conflicts of interest to declare. Bernice Dillon is a NICE employee and had no role in the production of the assessment report but contributed to the preparation of this manuscript. This summary of the Medical Technology Guidance was produced following the publication of the final guidance report. The article has not been externally peer reviewed by Applied Health Economics and Health Policy, but has been reviewed externally by NICE. Cedar was funded by the NICE Medical Technologies Evaluation Programme for its work.

Open Access This article is licensed under a Creative Commons Attribution-NonCommercial 4.0 International License, which permits any non-commercial use, sharing, adaptation, distribution and reproduction in any medium or format, as long as you give appropriate credit to the original author(s) and the source, provide a link to the Creative Commons licence, and indicate if changes were made. The images or other third party material in this article are included in the article's Creative Commons licence, unless indicated otherwise in a credit line to the material. If material is not included in the article's Creative Commons licence and your intended use is not permitted by statutory regulation or exceeds the permitted use, you will need to obtain permission directly from the copyright holder. To view a copy of this licence, visit http://creativecommons.org/licenses/by-nc/4.0/.

\section{References}

1. Campbell B, Campbell M. NICE medical technologies guidance: a novel and rigorous methodology to address a new health technology assessment challenge. Appl Health Econ Health Policy. 2012;10(5):295-7.

2. O'Connell S, Morgan H, Carolan-Rees G. MT457 Episcissors-60 for guided mediolateral episiotomy (external assessment report). 2019. Available at: https://www.nice.org.uk/guidance/mtg47/ documents/supporting-documentation. Accessed 14 Jan 2020.

3. National Institute for Health and Care Excellence. Episcissors-60 for mediolateral episiotomy [MTG47]. National Institute for Health and Care Excellence; 2020. Available at: https://www. nice.org.uk/guidance/mtg47. Last accessed 14 Jan 2020.

4. Thiagamoorthy G, Johnson A, Thakar R, Sultan AH. National survey of perineal trauma and its subsequent management in the United Kingdom. Int Urogynecol J. 2014;25(12):1621-7.

5. National Institute for Health and Care Excellence. Intrapartum care for healthy women and babies [CG190]. National Institute for Health and Care Excellence; 2017. Available at: https://www. nice.org.uk/guidance/cg190. Last accessed 14 May 2020.

6. Tincello DG, Williams A, Fowler GE, Adams EJ, Richmond DH, Alfirevic Z. Differences in episiotomy technique between midwives and doctors. BJOG Int J Obstet Gynaecol. 2003;110(12):1041-4.

7. NMPA Project Team. National Maternity and Perinatal Audit: Clinical Report 2019. Based on births in NHS maternity services between 1 April 2016 and 31 March 2017. London: RCOG; 2019. Available at: https://maternityaudit.org.uk/filesUploaded/NMPA\% 20Clinical\%20Report\%202019.pdf. Last accessed 07 May 2021.

8. Verghese TS, Champaneria R, Kapoor DS, Latthe PM. Obstetric anal sphincter injuries after episiotomy: systematic review and meta-analysis. Int Urogynecol J. 2016;27(10):1459-67.

9. NMPA Project Team. National maternity and perinatal audit: clinical report 2017. RCOG London; 2018.

10. Ramm O, Woo VG, Hung YY, Chen HC, Weintraub MLR. Risk factors for the development of obstetric anal sphincter injuries in modern obstetric practice. Obstet Gynecol. 2018;131(2):290-6.

11. Davies-Tuck M, Biro MA, Mockler J, Stewart L, Wallace EM, East C. Maternal Asian ethnicity and the risk of anal sphincter injury. Acta Obstet Gynecol Scand. 2015;94(3):308-15.

12. Freeman RM, Hollands HJ, Barron LF, Kapoor DS. Cutting a mediolateral episiotomy at the correct angle: evaluation of a new device, the Episcissors-60. Med Devices Evid Res. 2014;7:23-8.

13. Mohiudin H, Ali S, Pisal PN, Villar R. Implementation of the RCOG guidelines for prevention of obstetric anal sphincter injuries (OASI) at two London Hospitals: a time series analysis. Eur J Obstet Gynecol Reprod Biol. 2018;224:89-92.

14. Patel RP, Ubale SM. Evaluation of the angled Episcissors-60() episiotomy scissors in spontaneous vaginal deliveries. Med Devices Evid Res. 2014;7:253-6.

15. Sawant G, Kumar D. Randomized trial comparing episiotomies with Braun-Stadler episiotomy scissors and EPISCISSORS-60(). Med Devices Evid Res. 2015;8:251-4.

16. van Roon Y, Kirwin C, Rahman N, Vinayakarao L, Melson L, Kester N, et al. Comparison of obstetric anal sphincter injuries in nulliparous women before and after introduction of the EPISCISSORS-60 at two hospitals in the United Kingdom. Int J Women's Health. 2015;7:949-55.

17. Ayuk P, Robson S, Farnworth A, Rees J, Khunda A. Obstetric anal sphincter injuries (OASIs) before and after the introduction of the Episcissors-60: a multi-centre time series analysis. 2018. (Unpublished work).

18. Condell A, Bulchandani S, Burden F. Episcissors-reducing obstetric anal sphincter injuries (OASI) in instrumental delivery. BJOG Int J Obstet Gynaecol. 2018;125(Supplement 3):44.

19. Farnworth A, Ayuk P, Robson S. A pragmatic evaluation of barriers and facilitators to the implementation of an obstetric innovation (Episcissors) across maternity units in the North East and North Cumbria. Labour and Delivery. BJOG: Int J Obstet Gy. 2019;126:87-114. https://doi.org/10.1111/1471-0528.15635.

20. Lou YY, Thakar R, Sultan AH, Ajay B. Does Episcissors-60 reduce the incidence of obstetric anal sphincter injuries (OASI)? BJOG Int J Obstet Gynaecol. 2016;123(Supplement 2):51.

21. Ayuk P, Farnworth A, Rees J, Khunda A, Edmundson D, Raheja V, Ullal A, Ravimohan V, Lu E, Robson SC. Obstetric anal sphincter injuries before and after the introduction of the Episcissors-60: a multi-centre time series analysis. Eur J Obstet Gynecol Reprod Biol. 2019;241:94-8.

22. GRADEpro GDT: GRADEpro Guideline Development Tool [Software]. McMaster University, 2015 (developed by Evidence Prime, Inc.). Available from http://www.gradepro.org. Last accessed 22 July 2021.

23. Cochrane Review Manager software version 5.4.1 (September 2020). Available at: https://training.cochrane.org/online-learn 
ing/core-software-cochrane-reviews/revman/revman-5-download. Last accessed 22 July 2021.

24. York Health Economics Consortium (2017). Economic impact evaluation case study: Episcissors-60. Available at: https://www. medinvent.co.uk/assets/episcissors-economic-case-study-yhecaugust-2017.pdf.

25. NHS Improvement (2020). Reference cost collection: National Schedule of Reference Costs-Year 2017-18-NHS trust and NHS foundation trusts. NZ27Z post-natal therapeutic procedures. Available at: https://webarchive.nationalarchives.gov.uk/ 20200501111106/https://improvement.nhs.uk/resources/refer ence-costs/. Last accessed 14 May 2021.
26. Royal College of Obstetricians and Gynaecologists (2015) The management of third and fourth degree perineal tears. Green-top guideline 29. Available at: https://www.rcog.org.uk/en/guidelinesresearch-services/guidelines/gtg29/. Last accessed: 14 May 2021.

27. OASI Care Bundle Project Team. Implementation guide for maternity sites in the roll-out phase 2017-2018. RCOG London; 2018. Available at: https://www.rcog.org.uk/globalassets/documents/ guidelines/research--audit/oasi-care-bundle/oasi-care-bundleguide-final-_-050118.pdf. Last accessed: 28 June 2021. 